\title{
Effect of leaf size, thorn density and leaf accessibility on instantaneous intake rates of five woody species browsed by Matebele goats (Capra hircus L) in a semi-arid savanna, Zimbabwe
}

\author{
A. Sebata ${ }^{a, *}$, L.R. Ndlovu ${ }^{b}$ \\ ${ }^{a}$ Department of Forest Resources \& Wildlife Management, National University of Science E Technology, Bulawayo, Zimbabwe \\ ${ }^{\mathrm{b}}$ Vice-Chancellor's office, National University of Science E Technology (NUST), P.O. Box AC 939, Ascot, Bulawayo, Zimbabwe
}

\section{A R T I C L E I N F O}

\section{Article history:}

Received 11 September 2009

Received in revised form

3 March 2010

Accepted 21 May 2010

Available online $\mathrm{xxx}$

\section{Keywords:}

Browse

Inter-thorn spacing

Leaf accessibility indices

Plant morphology

Semi-arid

\begin{abstract}
A B S T R A C T
Browse instantaneous intake rate (IIR) is a product of bite size and bite rate which are constrained by plant morphology. We studied the effects of leaf size, thorn density and leaf accessibility on the IIRs of five browse species in semi-arid savanna over three leaf phenophases using cafeteria-style trials. Bite size was influenced by leaf size and bite rate by leaf accessibility, while thorn density had an impact on both bite size and bite rate. The lowest IIRs were recorded on the small leafed Acacia tortilis which also had the highest thorn density. Dichrostachys cinerea had the highest IIRs due to the large bite sizes. Although Terminalia prunioides and Commiphora pyracanthoides had small leaves, their arrangements in clusters allowed for higher IIRs, which were comparable to those of the large leafed $D$. cinerea. Instantaneous intake rate showed no clear trend in relation to leaf phenophase, although at early leaf the goats cropped smaller bites because of the small size of the newly sprouting leaves. We conclude that leaf size influenced IIRs through bite size, leaf accessibility through bite rate and thorn density through both bite size and bite rate.
\end{abstract}

(ㄷ) 2010 Elsevier Ltd. All rights reserved.

\section{Introduction}

In semi-arid south-western Zimbabwe goat production is the major source of livelihood. Goats contribute directly and indirectly to food security, education and social welfare (Homann et al., 2007). Farmers keep goats for cash income, meat, milk and manure. Goats in African savannas depend on browse (Dziba et al., 2003) which is available from December following early rains up to June in semiarid south-western Zimbabwe. In July most browse species which are deciduous shed off their leaves. This period coincides with start of feed shortages which persists up to December with peak shortages in October (Homann et al., 2007). The consequence of this is goat weight loss and high kid mortality. Homann et al. (2007) reported goat mortality of up to 45 percent, largely due to feed shortages. The major peak in birth is in April and coincides with availability of feed while a minor peak in births in August coincides with feed shortages (Homann et al., 2007). Mortalities due to feed shortages are therefore higher in kids born in August. Goats have to mobilize body reserves and forage on fallen dry leaves for their

\footnotetext{
* Corresponding author. Tel.: +263 9 282842; fax: +263 9286803

E-mail address: asebata1554@nust.ac.zw (A. Sebata).
}

energy requirements during the dry season. Goats, specifically hardy genotypes, are able to cope with nutrient deficiencies by efficient mobilization of body reserves (Alexandre and Mandonnet, 2005). In times of dietary sufficiency animals store surplus energy in the form of body fats which are then catabolized when dietary energy intake is inadequate to match the demands of production (Sibanda et al., 2000). Goat live weights start to increase from onset of rains and continue to increase until the early dry period when they decline rapidly (Sibanda et al., 2000). Nomadic goat herders follow feed resources to reduce the impact of seasonal insufficiencies on their animals (Sibanda et al., 2000). In sedentary systems goats need to maximize browse intake during the period when it is available to built large reserves for mobilization later when there are feed shortages. The availability of browse and its phenological changes influence its intake by browsers (Sanon et al., 2007).

Browse instantaneous intake rate is a product of bite size and bite rate. Illius and Gordon (1990) estimated that browsers crop between 10,000 and 40,000 bites per day from different individual plants. Different browse species will allow goats to crop varying number and size of bites leading to highly variable intake rates. Decisions made by the browser when selecting a bite have important consequences for its nutritional intake and hence fitness (Shipley et al., 1999). An understanding of the variation in browse 
instantaneous intake rate is thus desirable, especially in semi-arid savanna where browse shortages are prevalent. Cafeteria-style trials, which are more rapid and less expensive, can be used to compare different browse species instantaneous intake rates through determining bite size and bite rate over a limited period (Morand-Fehr, 2003). The number of bites represents a clear decision by the animal and can be counted easily by the researcher, while intake incorporates both number and size of bites taken per feeding time and represents the nutritional outcome of the diet selected (Illius et al., 1999). Instantaneous intake rates are constrained by plant morphology parameters such as leaf size, thorn density and inter-thorn spacing as browsers may not be able to select their optimal bite sizes or maximize bite rates due to the physiognomy (Shipley et al., 1999) or structural defenses of the plants (Cooper and Owen-Smith, 1986; Belovsky et al., 1991). Spalinger et al. (1986) suggested that browsers when afforded the opportunity to select from a range of plants of high nutritional quality, should base their selection more upon structural characteristics that affect handling time, than simply on dry matter digestibility or chemical composition. A study of these physical constraints will improve our understanding of variations in browse intake by browsers in semi-arid savanna.

We studied the instantaneous intake rates of five commonly browsed species Acacia tortilis, Terminalia prunioides, Dichrostachys cinerea, Commiphora pyracanthoides and Faidherbia albida (Timberlake and Mapaure, 1999) by measuring bite size and bite rate over three leaf phenophases in cafeteria-style trials. The three leaf phenophases selected were early leaf, representing high quality but low quantity browse, and full and mature leaf representing high quantity and low quality browse. We tested the following hypotheses: 1) instantaneous intake rates are influenced by leaf accessibility, thorn density and leaf size, 2) instantaneous intake rates vary with leaf phenophase.

\section{Materials and methods}

\subsection{Site description}

The study was carried out at Kwalu Communal lands $\left(21^{\circ} 25^{\prime} \mathrm{S}\right.$, $29^{\circ} 30^{\prime} \mathrm{E}$, altitude $1150 \mathrm{~m}$ a.s.l.), which is $415 \mathrm{~km}^{2}$ in size and $87 \mathrm{~km}$ northwest of Beitbridge town, Zimbabwe. Mean annual rainfall recorded over the last 30 years is $332.9 \mathrm{~mm}$ (range: $83-527$ ), with most of it falling during a single rainy season between November and April (Agritex, 1989). Mean monthly temperature ranges from $7.9^{\circ} \mathrm{C}$ to $33.6{ }^{\circ} \mathrm{C}$, with July recording the lowest and October the highest. The area is dry with a relative humidity of between $48 \%$ and $61 \%$ and a negative moisture balance (CESVI, 1999).

Soils are mostly moderately to very shallow and gravelly with those on basalt areas being brown clay loams to clays and often calcareous while those derived from gneiss are coarse-grained sands to sandy loams (Timberlake and Mapaure, 1999). Karroo sediments produce mostly medium grained unstructured sands, or bare rock.

The vegetation comprises a short, shrubby structure that varies from open to closed woodland (Timberlake and Mapaure, 1999). Prominent woody species in less disturbed ecosystems include $T$. prunioides, C. pyracanthoides, Grewia monticola, Grewia tenax and Colophospermum mopane. Disturbed ecosystems are dominated by A. tortilis. The herbaceous layer includes the gramenoid species; Eragrostis rigidior, Panicum maximum, P. coloratum and Urochloa mosambicensis and various forb species.

\subsection{Study plants}

Five commonly browsed species $C$. pyracanthoides Engl. subsp. pyracanthoides, T. prunioides C. Lawson, A. tortilis (Forssk.) Hayne subsp. heteracantha (Burch.) Brenan, F. albida (Delile) A. Chev. and D. cinerea (L.) Wight \& Arn subsp. nyassana (Taub.) Brenan)) were used. Details of the study species including phenology and morphology can be found in Coates Palgrave (2002) and Van Wyk and Van Wyk, 2001. A. tortilis is the predominant browse species in degraded ecosystems, $T$. prunioides and C. pyracanthoides in less degraded ecosystems, $D$. cinerea along drainage systems and $F$. albida along riparian ecosystems. All the woody species have thorns of different sizes, although $T$. prunioides thorns are blunt. The five species represent browse of variable leaf sizes, thorn density and leaf accessibility. C. pyracanthoides and T. prunioides have clustered leaves on lateral spiny branchlets while $A$. tortilis, $D$. cinerea and $F$. albida have compound leaves consisting of small leaflets (Coates Palgrave, 2002). A. tortilis has sharply hooked and straight thorns while $D$. cinerea and $F$. albida have straight thorns. $F$. albida has a unique reverse leaf phenology, i.e., it is in leaf in winter and loses its leaves in summer (Timberlake et al., 1999).

\subsection{Study animals}

The Matebele goats are small-framed animals with a characteristic mixture of colour patterns throughout the body and are well adapted to the harsh conditions of the semi-arid south-western Zimbabwe (Sibanda et al., 2000). The goats were penned at owner's homesteads overnight and then allowed to range freely, unattended, over the communally-shared rangeland during the day. The goats moved in flocks to known feeding sites, after release from the pens in the morning, where they fed before heading for the watering points (boreholes) at mid-afternoon. After drinking they headed back to the feeding sites and then finally in late afternoon they started their journey back to the pen walking slowly and feeding along the way. Kids are separated from their does overnight and the does are milked the following morning. Goats belonging to only one household were used in this study. Five lactating Matebele does with mean live weight of $31.23( \pm 0.27$, SE) kg were randomly selected from a flock of twenty-four for the study.

\subsection{Bite rate, bite size and intake rates}

Unbrowsed mature branches (terminal $70 \mathrm{~cm}$ ) of each species were collected on the morning of the trial and offered individually to each goat by mounting a branch vertically on a $45 \mathrm{~cm}$ long stake driven $15 \mathrm{~cm}$ into the ground in a feeding pen $(16 \mathrm{~m} \times 7 \mathrm{~m})$. The branches were mounted to simulate their positions on the trees. Branches were cut from the same height on each tree and were of relatively similar size, structure and leaf content within species to eliminate biases that could be induced by these factors (Dziba et al., 2003). Branch stems were soaked in water prior to use to reduce transpiration loss. Three branches from each browse species were kept as controls to correct for weight loss due to transpiration.

During trials, the goats were individually transferred into the feeding pen and allowed to feed on each offered browse species for a maximum of $3 \mathrm{~min}$ or up to a point where $75 \%$ of browseable material had been removed to ensure that foraging behaviour was not influenced by depletion of leaves on the branch (Green, 1984; Elston et al., 1996). Each goat feed for an average of $2.76 \mathrm{~min}$ $( \pm 0.14, \mathrm{SE})$. The goats were offered all the five browse species one at a time daily changing the order each day to avoid any conditioning and learning effects, as goats are known to have a good memory for tastes (Morand-Fehr, 2003). The selected goats were being milked and thus habituated to humans. The goats had been penned overnight and were moderately hungry. Silence was maintained during the trials. The trials were conducted between 9:00 am and 12:00 am each day. The trials were conducted over three periods: early 
Table 1

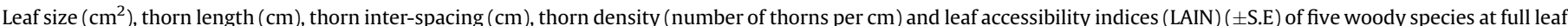

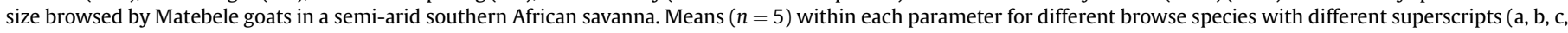
d) differ significantly $(P<0.001)$, based on Tukey test.

\begin{tabular}{|c|c|c|c|c|c|}
\hline Browse species & Leaf size & Thorn Length & Thorn inter-spacing & Thorn density & LAIN \\
\hline F. albida & $10.20^{\mathrm{a}}( \pm 0.86)$ & $1.08^{\mathrm{a}}( \pm 0.07)$ & $2.72^{\mathrm{a}}( \pm 0.21)$ & $0.90^{\mathrm{a}}( \pm 0.03)$ & $0.74^{\mathrm{a}}( \pm 0.02)$ \\
\hline D. cinerea & $12.60^{\mathrm{a}}( \pm 1.21)$ & $3.74^{\mathrm{b}}( \pm 0.34)$ & $3.20^{\mathrm{a}}( \pm 0.23)$ & $0.43^{\mathrm{b}}( \pm 0.08)$ & $0.90^{\mathrm{ac}}( \pm 0.09)$ \\
\hline T. prunioides & $4.78^{\mathrm{b}}( \pm 0.47)$ & $2.60^{c}( \pm 0.07)$ & $7.94^{\mathrm{b}}( \pm 0.26)$ & $0.20^{\mathrm{b}}( \pm 0.01)$ & $2.60^{\mathrm{b}}( \pm 0.15)$ \\
\hline C. pyracanthoides & $4.12^{\mathrm{b}}( \pm 0.27)$ & $1.88^{\mathrm{d}}( \pm 0.09)$ & $3.72^{c}( \pm 0.11)$ & $0.43^{\mathrm{b}}( \pm 0.02)$ & $1.18^{\mathrm{c}}( \pm 0.06)$ \\
\hline \multirow[t]{2}{*}{ A. tortilis } & $3.68^{\mathrm{b}}( \pm 0.37)$ & $0.40^{\mathrm{a}}( \pm 0.04)$ & $1.16^{\mathrm{d}}( \pm 0.22)$ & $1.60^{c}( \pm 0.10)$ & $0.34^{\mathrm{d}}( \pm 0.02)$ \\
\hline & $F_{4,20}=31.28$ & $F_{4,20}=63.84$ & $F_{4,20}=144.73$ & $F_{4,20}=97.35$ & $F_{4,12}=133.93$ \\
\hline
\end{tabular}

leaf (December 2007), full leaf (March 2008) and mature leaf (June 2008) for five consecutive days.

The number of bites counted during feeding and the time spent feeding were used to calculate bite rates (bites $\mathrm{min}^{-1}$ ), while bite sizes ( $\mathrm{g}$ bite $\mathrm{e}^{-1}$ ) were calculated from the difference between initial and residual branch mass (after correcting for transpiration loss) divided by the number of bites (Dziba et al., 2003). Intake rates, in grams dry mass (DM) per minute, were estimated as the product of bite rate and bite size (Allden and Whittaker, 1970; Ungar, 1996).

\subsection{Plant morphology measurements}

Plant morphology measurements on five terminal branches (50 cm lengths) of each woody species were made on the following:

\subsubsection{Leaf size $\left(\mathrm{cm}^{2}\right)$}

Five leaves of representative sizes of each browse species were collected at full leaf and leaf area $\left(\mathrm{cm}^{2}\right)$ estimated using a planimeter. For species with compound leaves the whole leaf was measured.

\subsubsection{Thorn length}

The thorns were characterized as straight or hooked or a combination of the two; and sharp or blunt. Although A. tortilis has two types of thorns: hooked and straight the branches used in this study only had hooked thorns. $D$. cinerea and $T$. prunioides thorns were sharp modified lateral shoots. F. albida and C. pyracanthoides had sharp thorns. The length of five thorns per browse species on each $50 \mathrm{~cm}$ terminal branch segment was measured to the nearest $\mathrm{cm}$.

Table 2

Relationships $(y=a+b x)$ of intake rates, leaf accessibility indices (LAIN), thorn density and leaf size $(y)$ of five woody species in semi-arid southern African savanna and various browse intake rate parameters $(x)$ achieved by Matebele goats when browsing on these plants $(n=14)$, ns - not significant, ${ }^{*}<0.05,{ }^{* *}<0.01$.

\begin{tabular}{|c|c|c|c|c|}
\hline & $r$ & $r^{2}$ & Regression equation & \\
\hline \multicolumn{5}{|l|}{ a) Intake rate $v s$} \\
\hline Bite size $(\mathrm{g})$ & 0.888 & 0.79 & $y=0.04+0.02 x$ & $* *$ \\
\hline Bite rate (bites $\min ^{-1}$ ) & 0.762 & 0.58 & $y=20.87+3.02 x$ & $* *$ \\
\hline b) Bite size $v s$ bite rate & 0.424 & 0.36 & $y=0.79+7.85 x$ & ns \\
\hline \multicolumn{5}{|l|}{ c) LAIN vs } \\
\hline Bite rate (bites $\min ^{-1}$ ) & 0.703 & 0.49 & $y=36.09+7.35 x$ & $* *$ \\
\hline Bite size $(\mathrm{g})$ & 0.450 & 0.20 & $y=0.14+0.03 x$ & ns \\
\hline Intake rate $\left(\mathrm{g} \min ^{-1}\right)$ & 0.618 & 0.38 & $y=4.97+1.63 x$ & $*$ \\
\hline \multicolumn{5}{|l|}{ d) Thorn density $v s$} \\
\hline Bite size $(\mathrm{g})$ & -0.572 & 0.33 & $y=0.12-0.03 x$ & * \\
\hline Bite rate (bites $\min ^{-1}$ ) & -0.658 & 0.43 & $y=31.79-6.42 x$ & $*$ \\
\hline Intake rate $\left(\mathrm{g} \mathrm{min}^{-1}\right)$ & -0.691 & 0.48 & $y=3.86-1.70 x$ & $* *$ \\
\hline \multicolumn{5}{|l|}{ e) Leaf size $\left(\mathrm{cm}^{2}\right) v s$} \\
\hline Intake rate $\left(\mathrm{g} \mathrm{min}^{-1}\right)$ & 0.725 & 0.53 & $y=0.87+0.20 x$ & $* *$ \\
\hline Bite size (g) & 0.598 & 0.36 & $y=0.05+0.05 x$ & $*$ \\
\hline Bite rate $\left(\mathrm{g} \mathrm{min}^{-1}\right)$ & 0.506 & 0.26 & $y=22.2+7.13 x$ & ns \\
\hline
\end{tabular}

\subsubsection{Inter-thorn spacing}

Measured as the distance (to nearest $\mathrm{mm}$ ) between adjacent thorns on the $50 \mathrm{~cm}$ terminal branch segments in five branches per woody species. Leaf accessibility indices (LAIN) were then calculated as inter-thorn spacing $(\mathrm{cm})$ divided by mean goat muzzle width (3.6) $( \pm 0.21, \mathrm{SE}) \mathrm{cm}$. The mean goat muzzle width was obtained from measurements of the goats used in the trial.

\subsubsection{Thorn density}

Number of thorns on a $50 \mathrm{~cm}$ terminal segment of the branch was counted in five branches per woody species and expressed as thorn density per $\mathrm{cm}$.

\subsection{Data analysis}

All data were tested for normality before analysis. Leaf accessibility indices, leaf size and thorn density data deviated from normality and were transformed using a natural logarithm transformation so it would exhibit homogeneity of variance (Zar, 1999). We used one way analysis of variance (ANOVA) in SPSS command (SPSS, 2002) to test for species differences in the plant parameters (leaf size, thorn length, thorn inter-spacing, thorn density and leaf accessibility indices) of the five browse species. When F-tests indicated significant differences, means were compared using posthoc Tukey HSD $(P<0.05)$.

The relationship between bite size, bite rate, intake rates, leaf accessibility indices, leaf size and thorn density were tested by Pearson's correlation and regression analysis in SPSS command (SPSS, 2002).

We used a mixed model with species and leaf phenophase as random factors and day of trial and individual goats as fixed factors to test for the effects of bite size, bite rate and instantaneous intake rate. The co-variates were thorn density, leaf size, thorn length and thorn inter-spacing. Species and leaf phenophase had significant effects on bite size, bite rate and instantaneous intake rate and were further analyzed using one way analysis of variance (ANOVA) in SPSS command (SPSS, 2002). When $F$-tests indicated significant differences, means were compared using post-hoc Tukey HSD $(P<0.05)$.

The natural logarithm of the ratio of instantaneous intake rates of each species relative to $A$. tortilis was calculated (Illius et al., 1999) to determine preference. The data were then analysed using one way analysis of variance with leaf phenophases as replicates. Species with high values on a log ratio scale are the most preferred species and those with low values are the least preferred species (Illius et al., 1999).

\section{Results}

\subsection{Leaf size, leaf accessibility indices (LAIN) and thorn density}

F. albida and $D$. cinerea had larger leaves than $T$. prunioides, $C$. pyracanthoides and $A$. tortilis (Table 1 ). Leaf size had a significant correlation with instantaneous intake rate and bite size (Table 2). $T$. 
Table 3

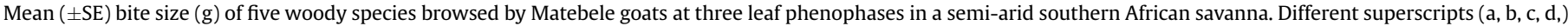
within leaf phenophase and $(A, B, C)$ within each species differ significantly $(P<0.001)$, based on Tukey test.

\begin{tabular}{|c|c|c|c|c|}
\hline \multirow[t]{2}{*}{ Browse species } & \multicolumn{3}{|l|}{ Leaf phenophase } & \\
\hline & Early leaf (Dec) & Full leaf (Mar) & Mature leaf (Jun) & \\
\hline F. albida & $0.11^{\mathrm{aA}}( \pm 0.002)$ & $0.13^{\mathrm{aB}}( \pm 0.002)$ & $0.14^{\mathrm{aC}}( \pm 0.002)$ & $F_{2,72}=59.94$ \\
\hline D. cinerea & $0.18^{\mathrm{bA}}( \pm 0.002)$ & $0.20^{\mathrm{bB}}( \pm 0.002)$ & $0.18^{\mathrm{bA}}( \pm 0.003)$ & $F_{2,72}=19.92$ \\
\hline T. prunioides & $0.12^{\mathrm{cA}}( \pm 0.002)$ & $0.14^{\mathrm{aB}}( \pm 0.002)$ & $0.13^{\mathrm{cC}}( \pm 0.001)$ & $F_{2,72}=20.85$ \\
\hline C. pyracanthoides & $0.15^{\mathrm{dA}}( \pm 0.002)$ & $0.18^{\mathrm{cB}}( \pm 0.002)$ & no leaf & $F_{1,48}=104.13$ \\
\hline \multirow[t]{2}{*}{ A. tortilis } & $0.07^{\mathrm{eA}}( \pm 0.002)$ & $0.09^{\mathrm{dB}}( \pm 0.004)$ & $0.08^{\mathrm{dB}}( \pm 0.004)$ & $F_{2,72}=12.67$ \\
\hline & $F_{4,120}=478.77$ & $F_{4,120}=130.66$ & $F_{3,96}=327.07$ & \\
\hline
\end{tabular}

prunioides had the highest LAIN and A. tortilis the least (Table 1). Leaf accessibility indices were positively correlated to bite rate and instantaneous intake rates (Table 2). A. tortilis had the highest thorn density and $T$. prunioides the least (Table 1 ). Bite size, bite rate and instantaneous intake rate had an inverse relationship with thorn density (Table 2). The correlation between thorn density and bite size was weaker than between thorn density and bite rate (Table 2).

\subsection{Bite size, bite rate and instantaneous intake rate}

Day of trial $(F=0.596, p=0.618)$ and individual goat $(F=0.568$, $p=0.637$ ) had no effect on bite size. Bite size varied with both species and leaf phenophase (Table 3). Smaller bites were cropped at early leaf and larger bites at full and mature leaf. Dichrostachys cineria had the largest bite size and $A$. tortilis the least.

Day of trial $(F=2.571, p=0.184)$ and individual goat $(F=1.474$, $p=0.464$ ) had no effect on bite rates. Leaf phenophase and species had significant effects on bite rate (Table 4). Bite rate was highest at early leaf and least at full leaf. T. prunioides had the highest bite rate and $A$. tortilis the least. The correlation between bite size and bite rate was not significant (Table 2 ).

Day of trial $(F=0.47, p=0.757)$ and individual goats $(F=4.917$, $p=0.204$ ) had no effect on instantaneous intake rate. Instantaneous intake rate of $D$. cineria was not influenced by leaf phenophase (Table 5). D. cineria had the highest instantaneous intake rate and $A$. tortilis the least. The correlation between instantaneous intake rate and bite size was stronger than between instantaneous intake rate and bite rate (Table 2 ).

\subsection{Preference}

The preference indices of the four browse species were similar (Fig. 1) and show that all the species were more preferred than $A$. tortilis.

\section{Discussion}

The cafeteria-style experiments offer an opportunity to compare instantaneous intake rates of browse species quickly. However, we should caution that mounting branches on stakes could have altered branch orientation affecting leaf accessibility and in turn influencing instantaneous intake rates.

To achieve higher instantaneous intake rates browsers have to select browse species that allow large bite sizes and higher bite rates. Factors that constrain both bite size and bite rate will reduce instantaneous intake rates. Leaf size influenced bite size with leaf accessibility having an effect on bite rate. Haschick and Kerley (1997) and Wilson and Kerley (2003) also found leaf size to influence bite size with bushbuck and boer goats. Species with higher leaf accessibility allowed higher bite rates as the goats could easily maneuver their mouths between thorns when plucking the leaves. Thorns restricted goat muzzle movement and also slowed down their ability to harvest browse by forcing them to become more careful in taking bites (Belovsky et al., 1991). The Matebele goats browsed on all the five species with a plucking action using front bites. Gowda (1996) reported boergoats as using front bites when foraging on spinescent species. Thorns have been shown to be more effective against browsers that forage by removing single leaves or leaf clusters with a plucking action (Haschick and Kerley, 1997). Browsers will achieve higher instantaneous intake rates through selecting species with higher leaf accessibility and larger leaves. However, handling time increases with increasing leaf size, suggesting that there is an optimum leaf size (Magadzire, 2002; Wilson and Kerley, 2003), this requires further investigation.

Thorn density had a negative impact on both bite size and bite rate (Wilson and Kerley, 2003) and thus instantaneous intake rates. Thorns reduce bite rates through higher cropping time (Belovsky and Schmitz, 1994; Magadzire, 2002) and bite size as a result of limited biting area (Cooper and Owen-Smith, 1986; Haschick and Kerley, 1997). The low instantaneous intake rates recorded on the smaller leafed $A$. tortilis support the findings of Cooper and OwenSmith (1986) that thorns are more effective as deterrents against ungulate herbivory when accompanied by small leaves.

Bite size and bite rate showed no relationship although other researchers reported an inverse relationship (Haschick and Kerley, 1997; Dziba et al., 2003; Aharon et al., 2007). Bite size had a stronger influence on instantaneous intake rate than bite rate (Haschick and Kerley, 1997; Agreil and Meuret, 2004). The goats will thus have to select browse with larger leaves to achiever higher instantaneous intake rates. However, most goat keepers regard $A$.

Table 4

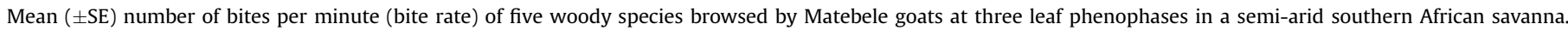
Different superscripts (a, b, c, d) within leaf phenophase and $(A, B, C)$ within each species differ significantly $(P<0.001)$ unless stated, based on Tukey test.

\begin{tabular}{|c|c|c|c|c|}
\hline \multirow[t]{2}{*}{ Browse species } & \multicolumn{3}{|l|}{ Leaf phenophase } & \\
\hline & Early leaf (Dec) & Full leaf (Mar) & Mature leaf (Jun) & \\
\hline F. albida & $45.62^{\mathrm{aA}}( \pm 0.16)$ & $36.00^{\mathrm{aB}}( \pm 0.10)$ & $37.68^{\mathrm{aC}}( \pm 0.13)$ & $F_{2,72}=1456.65$ \\
\hline D. cinerea & $39.46^{\mathrm{bA}}( \pm 0.17)$ & $36.10^{\mathrm{aB}}( \pm 0.11)$ & $37.37^{\mathrm{aC}}( \pm 0.13)$ & $F_{2,72}=148.41$ \\
\hline T. prunioides & $47.45^{\mathrm{aA}}( \pm 1.32)$ & $33.63^{\mathrm{bB}}( \pm 0.04)$ & $42.05^{\mathrm{bC}}( \pm 0.13)$ & $F_{2,72}=82.38$ \\
\hline C. pyracanthoides & $34.53^{\mathrm{cA}}( \pm 0.14)$ & $33.87^{\mathrm{bB}}( \pm 0.23)$ & no leaf & $F_{1,48}=5.87, P=0.019$ \\
\hline \multirow[t]{2}{*}{ A. tortilis } & $23.82^{\mathrm{dA}}( \pm 0.08)$ & $23.43^{\mathrm{cA}}( \pm 0.07)$ & $25.00^{\mathrm{cB}}( \pm 0.004)$ & $F_{2,72}=39.85$ \\
\hline & $F_{4,120}=247.76$ & $F_{4,120}=1630.55$ & $F_{3,96}=2346.40$ & \\
\hline
\end{tabular}


Table 5

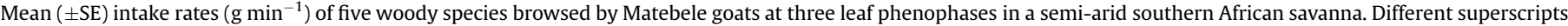
$(\mathrm{a}, \mathrm{b}, \mathrm{c}, \mathrm{d}$, ) within leaf phenophase and $(\mathrm{A}, \mathrm{B}, \mathrm{C})$ within each species differ significantly $(P<0.001)$ unless stated, based on Tukey test.

\begin{tabular}{|c|c|c|c|c|}
\hline \multirow[t]{2}{*}{ Browse species } & \multicolumn{3}{|l|}{ Leaf phenophase } & \\
\hline & Early leaf (Dec) & Full leaf (Mar) & Mature leaf (Jun) & \\
\hline F. albida & $4.85^{\mathrm{aA}}( \pm 0.10)$ & $4.87^{\mathrm{aA}}( \pm 0.08)$ & $5.59^{\mathrm{aB}}( \pm 0.13)$ & $F_{2,72}=15.98$ \\
\hline D. cinerea & $6.86^{\mathrm{b}}( \pm 0.15)$ & $6.96^{\mathrm{b}}( \pm 0.12)$ & $7.10^{\mathrm{b}}( \pm 0.13)$ & $F_{2,72}=0.82, P=0.447$ \\
\hline T. prunioides & $5.93^{\mathrm{cA}}( \pm 0.09)$ & $4.80^{\mathrm{aB}}( \pm 0.10)$ & $5.21^{\mathrm{cC}}( \pm 0.06)$ & $F_{2,72}=45.21$ \\
\hline C. pyracanthoides & $4.82^{\mathrm{a}}( \pm 0.08)$ & $5.40^{c}( \pm 0.14)$ & no leaf & $F_{1,48}=10.85, P=0.002$ \\
\hline \multirow[t]{2}{*}{ A. tortilis } & $1.37^{\mathrm{dA}}( \pm 0.08)$ & $1.92^{\mathrm{dB}}( \pm 0.08)$ & $1.85^{\mathrm{dB}}( \pm 0.08)$ & $F_{2,72}=14.67$ \\
\hline & $F_{4,120}=373.13$ & $F_{4,120}=287.25$ & $F_{3,96}=543.10$ & \\
\hline
\end{tabular}

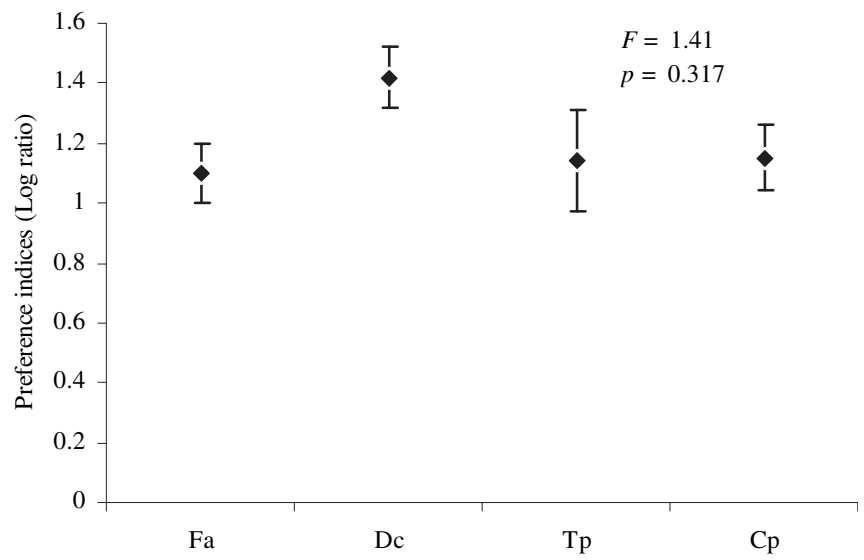

Fig. 1. Preference indices ( $\pm \mathrm{SE}$ ) of F. albida (Fa), D. cinerea (Dc), T. prunioides (Tp) and $C$. pyracanthoides $(\mathrm{Cp})$.

tortilis as the major browse species despite its low instantaneous intake rates, due to its high prevalence because of the heavy degradation of most communal rangelands and the subsequent high rate at which goats encounter it. $D$. cinerea had the highest instantaneous intake rates due to the large bites (Gordon et al., 1996; Ungar, 1996) and low thorn density. Wilson and Kerley (2003) suggested that high thorn density could overshadow large leaf size to reduce instantaneous intake rates. T. prunioides and $C$. pyracanthoides have small leaves arranged in clusters which were plucked off by the goats using front bites thereby increasing their instantaneous intake rates to closer to the large leafed F. albida and $D$. cinerea. We found no evidence that browsers compensate for reduced bite size by increasing bite rates as suggested by other researchers (Black and Kenney, 1984; Wickstrom et al., 1984; Hodgson, 1985).

At early leaf the goats cropped smaller bites due to the small size of the newly sprouting leaves. The goats relished the newly sprouting leaves following the dry season where they relied on dry fallen leaves and thus foraged quickly at early leaf. Instantaneous intake rate showed no clear trend in relation to leaf phenophase. In D. cinerea leaf phenophase had no influence on instantaneous intake rates.

Haschick and Kerley (1997) reported plant preference to be related to instantaneous intake rates. Although the log ratio preferences were not significantly different $D$. cinerea had a higher log ratio preference. This was further evidence that the instantaneous intake rates were largely influenced by leaf size.

\section{Conclusions}

It can thus be concluded that leaf size influenced instantaneous intake rates through bite size, leaf accessibility through bite rate and thorn density through both bite size and bite rate. Plants with clustered leaves are likely to be favoured by the browsers than large leafed plants since they require less handling time. The goats were intrinsically fast eaters on newly sprouting leaves after the first rains.

\section{References}

Agreil, C., Meuret, M., 2004. An improved method for quantifying intake rate and ingestive behaviour of ruminants in diverse and variable habitats using direct observation. Small Ruminant Research 54, 99-113.

Agritex., 1989. Agro-climatological Summaries and Analysis, Volume II. Department of Agriculture Technical and Extension Services/Department of Meteorological Services, Early Warning/Food Security Unit, Harare. Mimeo Report.

Aharon, H., Henkin, Z., Ungar, E.D., Kababya, D., Baram, H., Perevolotsky, A., 2007. Foraging behaviour of the newly introduced boer goat breed in a Mediterranean woodland: a research observation. Small Ruminant Research 69, 144-153.

Alexandre, G., Mandonnet, N., 2005. Goat meat production in harsh environments, Small Ruminants Research 60, 53-66.

Allden, W.G., Whittaker, I.A., 1970. The determinants of herbage intake by grazing sheep: the interrelationship of factors influencing herbage intake and availability. Australian Journal of Agricultural Research 21, 755-766.

Belovsky, G.E., Schmitz, O.J., 1994. Plant defenses and optimal foraging by mammalian herbivores. Journal of Mammalogy 75, 816-832.

Belovsky, G.E., Schmitz, O.J., Slade, J.B., Dawson, T.J., 1991. Effects of spines and thorns on Australian arid zone herbivores of different body masses. Oecologia $88,521-528$.

Black, J.L., Kenney, P.A., 1984. Factors affecting diet selection by sheep. II Height and density of pasture. Australian Journal of Agricultural Research 35, 565-578.

CESVI., 1999. Second semester report, September, 1999. Unpublished report. CESVI, Bulawayo.

Coates Palgrave, M., 2002. Keith Coates Palgrave Trees of Southern Africa. Struik Publishers, Cape Town South Africa, p. 959.

Cooper, S.M., Owen-Smith, N., 1986. Effects of plant spinescence on large mammalian herbivores. Oecologia 68, 446-455.

Dziba, L.E., Scogings, P.F., Gordon, I.J., Raats, J.G., 2003. Effects of season and breed on browse species intake rates and diet selection by goats in the False Thornveld of the Eastern Cape, South Africa. Small Ruminant Research 47, 17-30.

Elston, D.A., Illius, A.W., Gordon, I.J., 1996. Assessment of preference among a range of options using log ratio analysis. Ecology 77, 2538-2548.

Gordon, I.J., Illius, A.W., Milne, J.D., 1996. Sources of variation in the foraging efficiency of grazing ruminants. Functional Ecology 10, 219-226.

Gowda, J.H., 1996. Spines of Acacia tortilis: what do they defend and how? Oikos 77, 279-284.

Green, R.F., 1984. Foraging rules for optimal foragers. American Naturalist 123, 30-40.

Haschick, S.L., Kerley, G.I.H., 1997. Browse intake rates by bushbuck (Tragelaphus scriptus) and boergoats (Capra hircus). African Journal of Ecology 35, 146-155.

Hodgson, J., 1985. The control of herbage intake in the grazing ruminant. Proceedings of the Nutrition Society 44, 339-346.

Homann, S., van Rooyen, A., Moyo, T., Nengomasha, Z., 2007. Goat Production and Marketing: Baseline Information for Semi-arid Zimbabwe. International Crops Research Institute for the Semi-Arid Tropics (ICRISAT), Bulawayo, Zimbabwe. $1-84$.

Illius, A.W., Gordon, I.J., 1990. Constraints on diet selection and foraging behaviour in mammalian herbivores. In: Hughes, R.E. (Ed.), Behavioural Mechanisms of Food Selection. Springer, Berlin, Germany, pp. 369-393.

Illius, A.W., Gordon, I.J., Elstron, D.A., Milne, J.D., 1999. Diet selection in goats: a test of intake-rate maximization. Ecology 88, 1008-1018.

Magadzire, Z., 2002. Foraging strategies of cattle and goats in mixed-species grazing systems. PhD Thesis, University of Edinburgh.

Morand-Fehr, P., 2003. Dietary choices of goats at the trough. Small Ruminant Research 49, 231-239.

Sanon, H.O., Kaboŕe-Zoungrana, C., Ledin, I., 2007. Behaviour of goats, sheep and cattle and their selection of browse species on natural pasture in a Sahelian area. Small Ruminant Research 67, 64-74. 
Shipley, L.A., Illius, A.W., Danell, K., Hobbs, N.T., Spalinger, D.E., 1999. Predicting bite size selection of mammalian herbivores: a test of a general model of diet optimization. Oikos 84, 55-68.

Sibanda, L.M., Bryant, M.I., Ndlovu, L.R., 2000. Live weight and body condition changes of Matebele does during their breeding cycle in a semi-arid environment. Small Ruminant Research 35, 271-275.

Spalinger, D.E., Robbins, C.T., Hanley, T.A., 1986. The assessment of handling time in ruminants: the effect of plant chemical and physical structure on the rate of breakdown of plant particles in the rumen of mule deer and elk. Canadian Journal of Zoology 64, 312-321.

SPSS, 2002. SPSS Version 11.5 for Windows. SPSS Inc., Chicago, USA. www.spss.com. Timberlake, J., Fagg, C., Barnes, R., 1999. Field Guide to the Acacias of Zimbabwe. CBC Publishing, Harare, Zimbabwe, pp. 1-160.

Timberlake, J.R., Mapaure, I., 1999. Vegetation Survey of Maramani/Tuli area, southwest Zimbabwe. In: Timberlake, J., Mapaure, I., Chapano, C. (Eds.), Vegetation
Survey of Parts of the Southern Lowveld, Zimbabwe. Occasional Publications in Biodiversity, No. 6. Biodiversity Foundation for Africa, Bulawayo/Zambezi Society, Harare, Zimbabwe.

Ungar, E.D., 1996. Ingestive behaviour. In: Hodgson, J., Illius, A.W. (Eds.), The Ecology and Management of Grazing Systems. CAB International, Oxon, UK, pp. 185-218.

Van Wyk, A.E., Van Wyk, P., 2001. Field Guide to Trees of Southern Africa. Struik Publishers, Cape Town, South Africa.

Wickstrom, M.L., Robbins, C.T., Hanley, T.A., Spalinger, D.E., Parish, S.M., 1984. Food intake and foraging energetics of elk and mule deer. Journal of Wildlife Management 48, 1285-1301.

Wilson, S.L., Kerley, G.I.H., 2003. The effect of plant spinescence on the foraging efficiency of bushbuck and boergoats: browsers of similar body size. Journal of Arid Environments 55, 150-158.

Zar, J.H., 1999. Biostatistical Analysis, fourth ed. Prentice-Hall, Englewood Cliffs, New Jersey. 